\title{
Survey on Perceptions, Attitudes, and Experiences of Women Officers and Engineers onboard Malaysian Vessels
}

\author{
Norhaslinda Binti Yunus ${ }^{1, a, *}$, and Mohd Hafizi Said ${ }^{2, b}$ \\ ${ }^{1}$ Program of Nautical Science and Maritime Transportation, School of Ocean Engineering, \\ Universiti Malaysia Terengganu, Kuala Terengganu, Malaysia \\ ${ }^{2}$ School of Ocean Engineering, Universiti Malaysia Terengganu, Kuala Terengganu, Malaysia \\ a.norhaslinda.yunus@yahoo.com,b.hafizi@umt.edu.my \\ *corresponding author
}

Keywords: $\quad$ Career At Sea, Malaysian Seafarers, Women Seafarer

\begin{abstract}
Seafaring profession was well known as a male-dominated profession. The acceptance of women onboard always being an issue, as they are always being questioned whether the seafaring career fits women very well. Perceptions, attitudes, and experiences of women officers and engineers onboard the Malaysian vessel may influence the retention of women in the seafaring profession. The retention of women in the industry can affect negatively by lack of trust that facilitates cooperation among crew members onboard. An online survey was conducted in order to gather data on perception towards Malaysian women seafarer from the perspectives of the men colleagues. The data collected being analysis into statistical analysis. Research conducted limited to Malaysian seafarers only. The results of the analysis revealed that while the majority of male seafarers realize when it comes to profession, women and men are equals while majority of them believes that women can perform the task well. $98 \%$ out of 60 respondents agreed that women seafarer always give good cooperation in performing tasks and male colleagues appear satisfied with the ability of women seafarer to cope up with the responsibilities. As conclusions, this research can contribute to the design and development of policy measures that can contribute to the integration of women in the seafaring career at the same time can increase of the retention rate of those already employed, also provide interesting insights on the issue.
\end{abstract}

\section{Introduction}

Recently the need for women to take up economically productive and challenging jobs outside the family has increased due to the need for contributing towards the economic betterment of the families, compared to the traditional role of women only limited to daily chores of household activities. The proportion of women express willing to join many challenging professions is very meager and maritime sector is one among them. Maritime sector is known as a well male-dominated field, to be specific, shipping. Access of women into maritime industry is still restrained by many developed 
countries. The same scenario happened in Malaysia. As a maritime nation, the involvement of women in seafaring career is gradually increasing, even though the trend seems really new to the people and environment of Malaysia. Shipping sectors still preserve a male-dominated culture compared to other sectors. It is even more profound where women make up only $2 \%$ of the workforce in the traditionally male-dominated maritime industry [1]. In 2006, the first batch of 18 female cadets enrolled at maritime institutions (ALAM) for Diploma in Nautical Studies and Marine Engineering [2]. As per year 2016, a total of 55 women seafarers hired in Malaysia [3]. Even though the maritime industry has adopted initiatives towards the integration of women into the maritime industry, the rate of participation of women is at sluggish rate.

\section{Literature Review}

\subsection{Perception}

There will be positive and negative perceptions about women pursuing the seafaring career. For those who have positive perceptions about seafaring career it will automatically encourage the women to pursue this career. But for those who have negative perceptions, it will influence the pace of growth or decline of the population of women that enter or remain in the seafaring profession. Studies stated [4] that there were both positive and negative perceptions about involvements of women in seafaring career in Asia. Positive perceptions were that Asian women were being adventurous; they loved challenges, could easily adjust to new environment and were hard working. While the negative perceptions were that women were potential sources of trouble to marital relationships of their male counterparts, there was inequality in task distribution on board as women were looked at as the weaker sex and furthermore the women were prone to harassment [4]. A career at sea for a Malaysian woman is full of obstacles and certainly not very much promoted as compared with other occupations due to the typically traditional view that a woman should be a housewife.

\subsection{Attitude}

Become a women seafarer is not easy. This profession has become a male-dominated career for centuries. It would be very rare for women to get into the seafaring career and be recognized. However, there are still women facing the wave of resistance. Women became more courageous, determined and challenged to equal men if not surpass in the seafaring profession instead of being disappointed and discouraged to pursue the career. Obviously, maritime industry follows the rule of biology, that customarily or traditionally, men are to dominate women. Particular strengths nature has given women for duties in the home where women are well suited for supportive, care taking occupations and professions while men, under demanding circumstance are equipped to exercise power and function [5]. Curiosity often occurs on how a woman can face and adapt to the working environment on board ship. Besides, the separation from family can be major concern and the source of how much happiness for males as well as for females. According to [6] isolation is common for all seafarers, but for a woman the isolations can be more difficult, especially if you are the sole woman among male crew during six months of more or less continuously boarding.

\subsection{Experience}

Study on women seafarers employed on cargo ships in the EC fleet in 1998 by Seafarers International Research Centre's found that women feel constantly watched and compelled by their male shipmates to work to the limits of their endurance. [7]. Women seafarers always feel pressured to prove their ability by having to work harder or by taking on the more demanding tasks. The 
obstacles and difficulties faced by women working on board ship are many and they vary between countries. Seafaring basically a male-dominated career which often hostile, have to confront discrimination, sexual harassment, bullying, and violence environment. After they have acquired the necessary training and knowledge of running a ship, companies hiring these women are actually preparing them for office positions where women are more appropriate and well suited with the office job. In order to overcome all kinds of obstacles and challenges that may come in seafaring profession, women seafarer must be physically, emotionally, and spiritually tough [8].

\section{Methodology}

As the aim of the research was to examine the perceptions, attitudes, and experiences of women officers and engineers on board Malaysian vessels, the choice was made to conduct it with a specially developed questionnaire. With regard to data collection, the choice was to design and develop an online questionnaire and to organize an online survey. Advantages of the online survey are flexibility, convenience, and the possibility to reach large samples, control among the major strengths of the online survey. To get the data for my research, the online questionnaire has been set up, distributed among the seafarers in Malaysia. The questions asked are in line with the topic issues of the research. Perceptions, attitudes, and experiences of women officers and engineers on board Malaysian vessels are known.

The questionnaire consisted of 15 questions developed in three sections. The first section included 5 questions that related to their general information who work in seafaring at Malaysia. The second section included 4 questions which targeted those seafarers about the perception on woman seafarer. The aim was to identify the level of acceptance of woman seafarer in maritime industry or on-board ship. The third section included 6 questions focusing on the attitudes and experience of women seafarer based on respondent or another seafarers view. The research designs are accordingly to Figure 1 shows below.

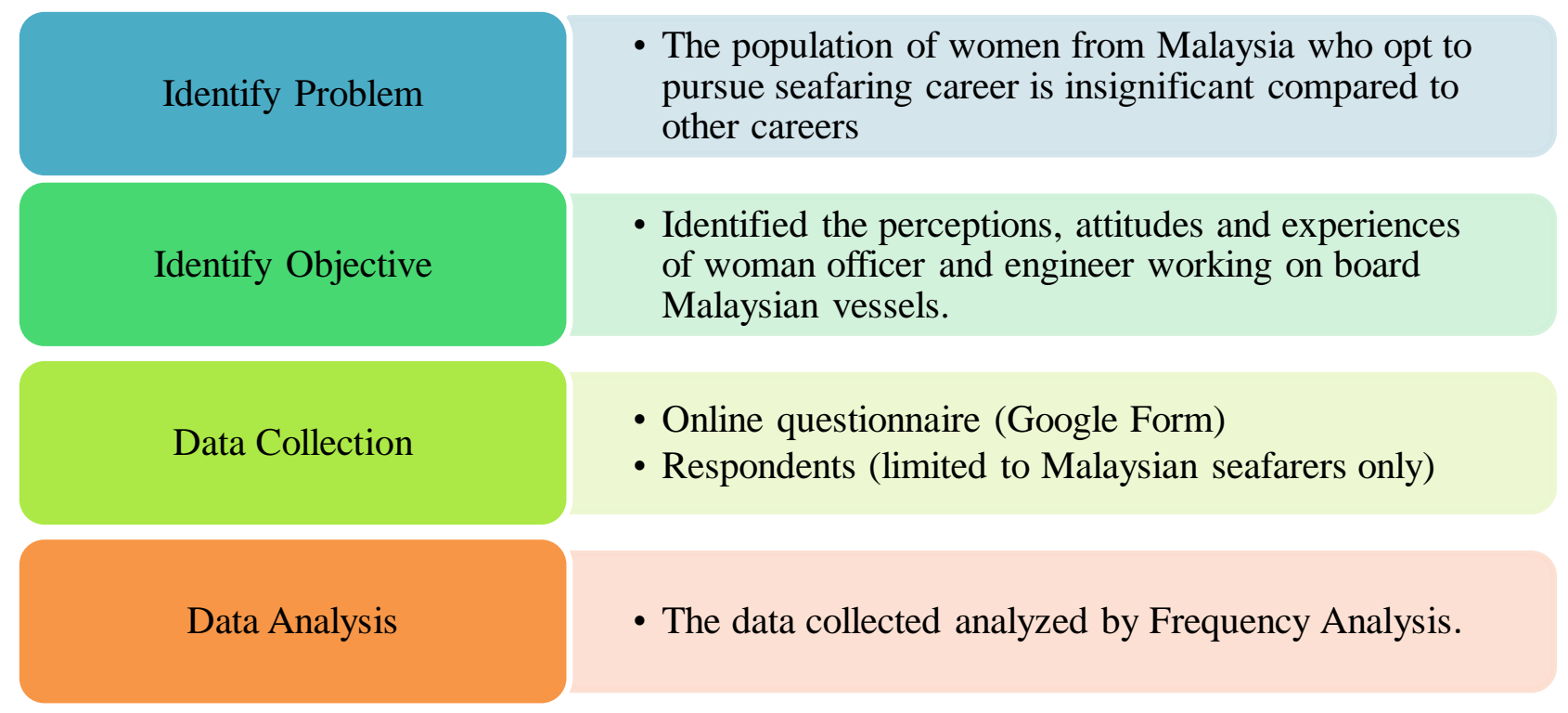

Figure 1: Research Design 
The questionnaire was posted in various seafaring profession groups and in social media applications. The respondents are supposed to give opinion about the involvement of women in seafaring profession. The online questionnaire consists of question that needs the respondents to choose 'yes' or 'no' as their answer. In total, 60 valid questionnaires were collected. All the respondents were consisted from operational level (junior officers, junior engineers, and other officer levels) and management level (captains, chief engineers, chief officers and second engineers) on board ship.

Table 1: The Rank of Respondents

\begin{tabular}{|l|c|c|}
\hline \multicolumn{1}{|c|}{ Rank } & $\begin{array}{c}\text { Number of } \\
\text { respondents }\end{array}$ & Percentage \% \\
\hline Management Level & 42 & 70 \\
\hline Operational Level & 16 & 25.8 \\
\hline Ratings & 2 & 3.2 \\
\hline TOTAL & 60 & 100.0 \\
\hline
\end{tabular}

\section{Results and Findings}

All 60 respondents have experienced working with women on board. The first question concerned with their opinion whether the working conditions of seafarers' favor women. For $83.3 \%$ of them agreed that the working conditions on board ship favor women. Women are actually can get used to the working environment onboard despite long separation from family and the fact those working on board are less glamorous compared to industry's marketing portrayed. Even others might felt that women could work at sea but limited to certain types of ship and only in positions that did not conflict with general roles of women, thus women could work in rank such as assistant cook, radio officer, steward or in hotel and catering departments aboard cruise ships. Particularly, the engine room was seen as the least suitable for women with its associated images of physically heavy demanding work tasks as well as heat, sweat, and dirt. Nowadays in the digitalized and automated world, most of physical labor is mostly taken over by machine and women also can work better as men.

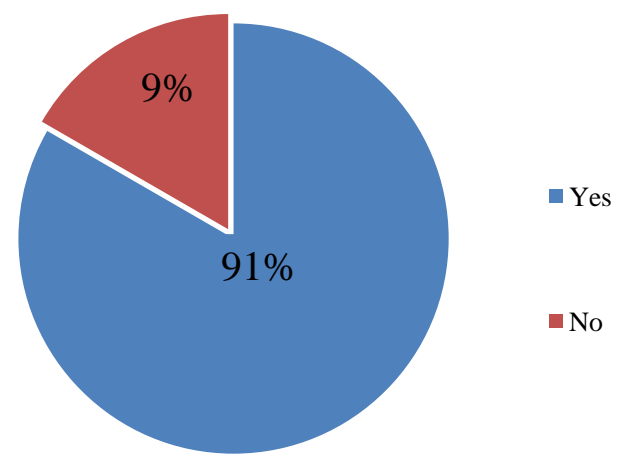

Figure 2: Seafarers Working Condition Favor Women 
Respondents were also asked whether they believed that female seafarers can cope up with the job and responsibilities. 83.3\% of them agreed that women can cope up with the responsibilities given. Meaning that women are compatible with the seafaring profession, even though the traditional role of women is just being around their families and just doing the motherhood duties and household chores. Even though ships have been overwhelmingly dominated by men for hundreds of years, but women be able to cope up with job. Yet, some also response that women can only cope up to limited task while some response that women cannot cope up to some heavy and complicated task.

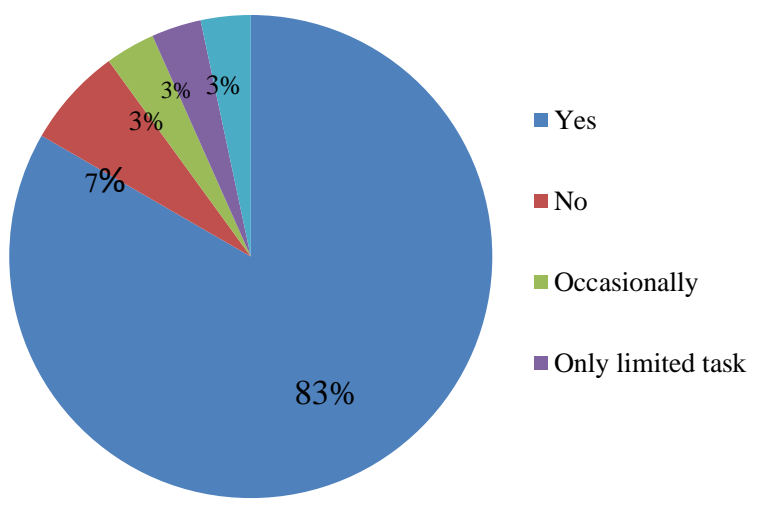

Figure 3: Respondents agreed women seafarers can cope up with responsibilities

Out of 60 respondents, 58 of them agreed that women seafarer always give a good cooperation in working or performing tasks. This finding is also consistent with their attitude to the perspective of cooperation with a woman as a crew member onboard. So, women shall be given same tasks as their male counterpart because it was proven that women seafarers can give good cooperation in performing tasks.

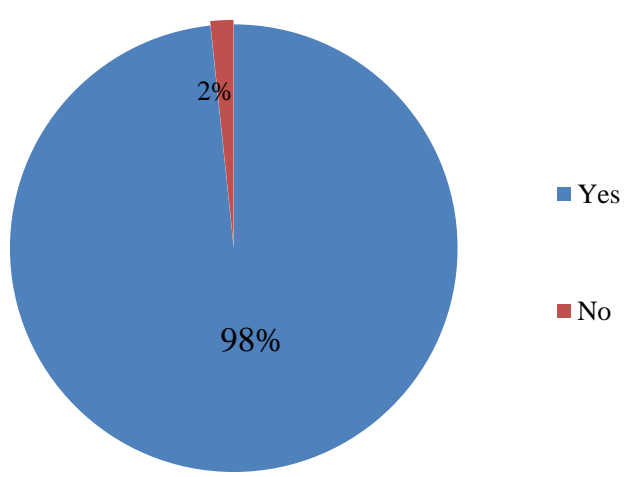

Figure 4: Respondents Agreed Women Seafarers Always Give Good Cooperation in Working/Performing Tasks

In addition to that, 44 of respondents believe that the female seafarer shall not be treated differently just because they are women. Respondents believed that even being the sole women among men does not mean that women shall be treated differently. Men and women shall be treated equally despite their gender. This means both men and women need equal access to shipping industry. From the survey, concluded that gender discrimination can be eliminated and increased the employment rate of women seafarers. 


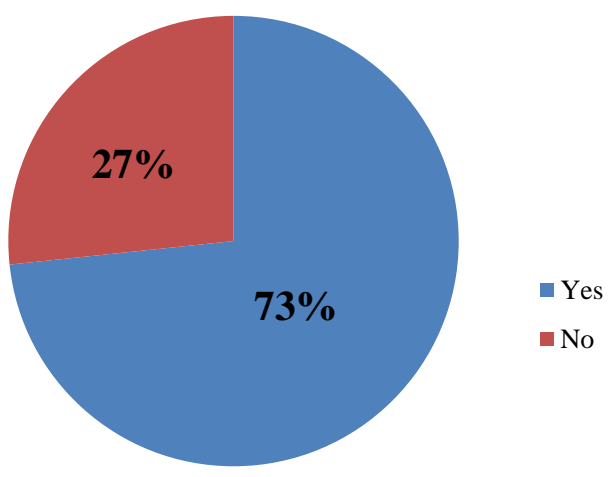

Figure 5: Respondents agreed women seafarer shall not be treated differently because they are women

From the online questionnaire, $77 \%$ of respondents agreed that women tend to perform in the same range as the man does. This shows that woman can perform all the tasks onboard during training or in the course of her career and that she can do it as well as any man. Despite nature of seafaring career as a challenging and male-dominated industry, this survey proved that women shall be given the opportunities to perform and excel in seafaring profession. Furthermore, living in the era of globalization, needs of women to contribute to the betterment of their families being one of the factor involvements of women in the seafaring career.

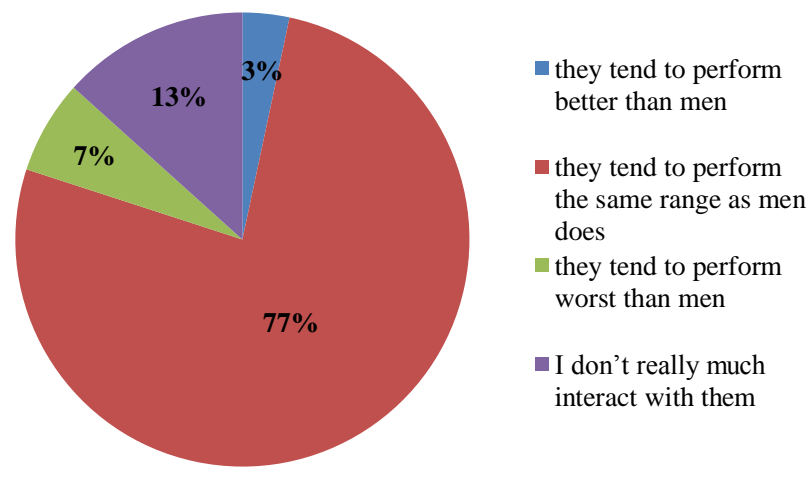

Figure 6: Respondents agreed that women seafarers tend to perform the same

\section{Discussion}

Specifically, those who had experience of working with a woman as a crew member onboard were asked to state their agreement or disagreement with the statement whether "will they marry women seafarer". 36 out of 60 respondents $(58.1 \%)$ agreed with the statement that 'yes', they will marry women seafarers. This proves that women seafarers are positively accepted to the on board community. 


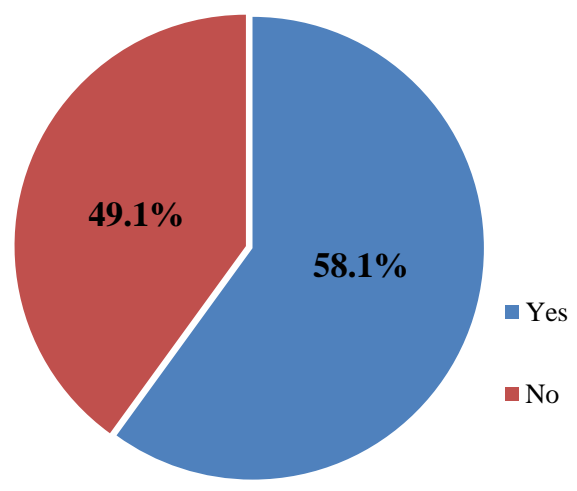

Fig. 7. Respondents stated their agreement of the statement

$58.1 \%$ of respondents also stated their agreement that will recommend the seafaring profession to their female relatives and friends. From this, it shows that seafarers adapted well to the presence of women colleagues on board, despite of many who are not exposed to seafaring environment are still having bad perspectives towards women pursue their seafaring career.

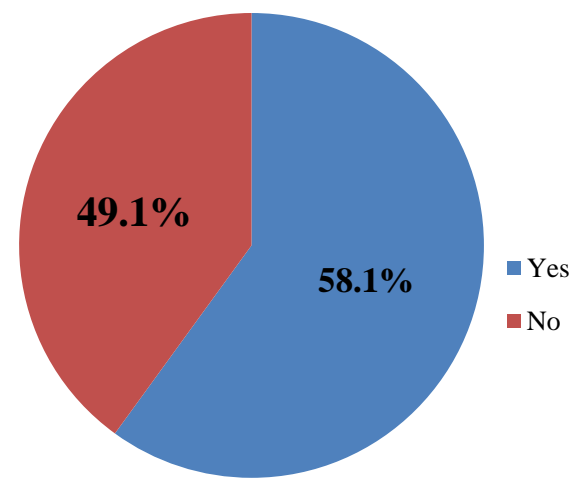

Fig 8. Respondents stated their agreement with the statement

\section{Conclusions}

The perception, attitudes and experiences of women working on board ship are varies between countries. Basically, seafaring is a male dominated career which the workplace are often hostile, environment have to confront bullying, discrimination, sexual harassment, and violence. Despite the obstacles and challenges women faced, there might be women who were considerable very passion with their career at sea, with the determination and dedication to succeed in seafaring career. A number of initiatives need to be taken, including active promotion of seafaring as a potential career for female in order to motivate the joining and pursuing of women in seafaring career. The perception of seafaring as a men-dominated career or the gender stereotypes of other maritime companies, all crewing and shipping companies shall implement policies addressing sexual harassment. The placement of female crewmembers on board should occur so that they are not the lone female onboard, where possible. From the research it was realized that seafaring as an existing career that could be pursued. However, there were misconceptions that the career was strenuous and associated with a lot of risk. It was quite obvious that people in Malaysia did not know much about the technological developments in ships and seafaring, which had made seafaring less strenuous. Those 
who had very little or no experience working with women onboard typically have the negative expressions about women seafarer.

\section{Acknowledgements}

The success and final outcome of this research required a lot of guidance. I am extremely privileged to have got this all along the completion of my research. I respect and thank you to all lecturers from the School of Ocean Engineering for providing me an opportunity to do a research and giving me all support and guidance.

\section{References}

[1] International Transport Workers Federation, 2018. Accessed on Jan 18, 2018.

[2] ALAM Maritime Academy 2018. Accessed on Jan 15, 2018. Available web: http://www.alam.edu.my/about-us/theacademy/milestones-and-success-stories/

[3] Malaysia International Shipping Company (MISC), (2017). Info graphic on women seafarers. Available web: http://www.misc.com.my/media/2136/woman-seafarers-nurturing-future-seafarers.pdf

[4] Capellan E. R. (2013). Problems encountered by women seafarers on board ships.

[5] Nanda S. Purandaré (2011). Democracy by Assocation: A Comparative Exploration of the Effects of Inequality and the State on Civic Engagement. Department of Political Science, University of Toronto.

[6] KITADA, M. 2010, Women Seafarers and their Identities.

[7] M. Zhao, Women seafarers in the EC, Seafarers' International Research Centre, Cardiff, 1998.

[8] M. Magramo, G. Eler, Women Seafarers: Solution to Shortage of Competent Officers 